\title{
CANCER PAIN MANAGEMENT: ROLE OF INTRATHECAL ALCOHOL: A CASE REPORT
}

K. Upendra Singh ${ }^{1}$, Kh. Lokeshwar Singh2, S. Thoibahenba Singh³, N. Charan4, Jonan Puni Kay ${ }^{5}$

\section{HOW TO CITE THIS ARTICLE:}

K. Upendra Singh, Kh. Lokeshwar Singh, S. Thoibahenba Singh, N. Charan, Jonan Puni Kay. "Cancer Pain Management: Role of Intrathecal Alcohol: A Case Report". Journal of Evolution of Medical and Dental Sciences 2015; Vol. 4, Issue 14, February 16; Page: 2418-2421, DOI: 10.14260/jemds/2015/349

ABSTRACT: A 34 year old lady was found to be in acute pain due to metastatic phaeochromocytoma following involvement of L5, S1 \& S2 vertebrae. She was treated with series of MIBG scanning and ablation and surgical option was refused by the patient. She was suffering from rapidly increasing radicular pain of the lower limbs which was being managed with oral and injectable opioids. The team of doctors treating her decided to give epidural opioids and bupivacaine initially but the total dose of the drug and frequency was found to be gradually increased. Therefore, continous administration of intathecal opiods and bupivacaine was given but the same problem occured after a few weeks and pain relief was minimal. Ultimately intrathecal absolute alcohol was given as there were no more options left. The patient had dramatic pain relief till her death.

KEYWORDS: Phaeochromocytoma, epidural, intrathecal, morphine, bupivacaine, alcohol.

INTRODUCTION: Phaeochromocytoma, a tumour of the adrenal medulla, deriving from chromaffin cells produces catecholamines. Approximately $10 \%$ of them are malignant. Metastasis commonly occurs to lymph nodes, bone and liver. Surgical excision is the only chance to cure. Other considerations are tumour debulking, treatment with I-MIBG (Iodine-131-meta-iodobenzylguanidine) or combination chemotherapy.

CASE HISTORY: A 34 year old Hindu female patient had phaeochromocytoma excision in 1994. She remained symptom free, leading a normal life till 2006 when she was diagnosed to have metastatic pheochromocytoma with involvement of L5, S1 \&S2 vertebrae and left axillary lymph nodes. Traces of metastatic lesions were seen in the liver, heart, salivary glands and urinary bladder. She had series of MIBG scanning and ablation in2009. Surgical option for metastatic lesions of the vertebrae was refused by the patient and was managed conservatively. She had rapidly increasing radicular pain in both lower limbs and was managed with oral and injectable morphine.

When first examined, she was bed-ridden with intractable radicular pain in both lower limbs, $\mathrm{R}>\mathrm{L}$, catheterized and crying with pain. Except for mild tachycardia she was normotensive and other vital parameters were within normal limits. Examination of nervous system revealed normal CNS functions; motor function of Grade 3 in the right lower limb \& Grade 4 in the left lower limb. Even a slight movement aggravated the pain tremendously. There was an obvious bony swelling anteriorly on the right chest wall. The patient was taking tab gabapentin $300 \mathrm{mg}$ OD, tab amitryptyllin 50mg OD, tab morphine $20 \mathrm{mg}$ QID, parenteral morphine 30 to $60 \mathrm{mg}$ and antihypertensives daily.

No other investigations were ordered as the treatment plan was to relieve the intractable pain as much as possible. A team of doctors was formed as the goal of treatment was quite clear and the patient had to be managed at her residence. An epidural catheter was sited at L3-4 intervertebral space and a bolus dose of $1.5 \mathrm{mg}$ morphine in $10 \mathrm{ml}$ of $0.125 \%$ bupivacaine was given. Her pain was 


\section{CASE REPORT}

relieved dramatically after about 15 minutes. She was maintained with the bolus epidural injections 2 to 3 times daily. In a few days, the concentrations of bupivacaine had to be increased to $0.25 \%$ and breakthrough pain was managed with epidural bolus of $10 \mathrm{ml}$ bupivacaine $0.25 \%$ and parenteral morphine 10 to $15 \mathrm{mg}$. By the end of 1 week, her morphine consumption and frequency of epidural injections were increasing. It was decided to give an epidural dose of depot methyl prednisolone in the hope that it may reduce neuraxial tissue oedema and improve pain relief but was to no avail. At the end of 2 weeks, it was decided to change the epidural catheter and start continuous infusion of epidural narcotics and bupivacaine.

The dura was inadvertently punctured with the 18G Touhy needle and the plan was changed to put the epidural catheter intrathecally. $25 \mathrm{ug}$ of fentanyl, 100ugof morphine and $0.5 \mathrm{ml}$ bupivacaine heavy $0.5 \%$ were injected. The pain relief was excellent and patient was maintained on this regime, repeating 2-3 times daily. By the fifth day, CSF was found dripping out through the skin and the catheter had to be removed. Epidural catheter was reinserted at the lower inter-space and continuous infusion @ $5 \mathrm{ml}$ per hour of $0.2 \%$ bupivacaine $+25 \mathrm{ug} / \mathrm{ml}$ morphine $+2 \mathrm{ug} / \mathrm{ml}$ fentanyl was started. Again, the dose requirement was increasing and pain relief was minimal after about one week. The dripping of CSF was no more seen and it was decided to switch over to continuous intrathecal infusion.

Unfortunately intrathecal catheters were not available at that time and we were left with the only option of using the epidural catheter as intrathecal catheter. Patient was started on hourly intrathecal infusion of $0.5 \mathrm{ml}$ of $0.125 \%$ bupivacaine $+30 \mathrm{ug}$ morphine. After 2 days her pain could no longer be relieved and bolus infusion of $2 \mathrm{ml}$ of $0.5 \%$ heavy bupivacaine through the catheter produced no pain relief even though free fluid (CSF) could be aspirated through the catheter. To confirm the intrathecal siting of the catheter the aspirated fluid was sent for laboratory examination and the report (Table 1) was suggestive of CSF.

\section{CSF ANALYSIS:}

\begin{tabular}{|c|c|}
\hline Physical & Vol $=2 \mathrm{ml}$, turbid, coagulum + \\
\hline Chemical & Protein $=0.5 \mathrm{gm} / \mathrm{dl}$, Sugar $=400 \mathrm{mg} / \mathrm{dl}$ \\
\hline Microscopic & TLC $=755 / \mathrm{mm}^{3}, \mathrm{P}_{98}, \mathrm{~L}_{2}$, Metastatic cell= nil \\
\hline & Table 1 \\
\hline
\end{tabular}

The only option left of was intrathecal neurolytic block. So neurolysis with either phenol or absolute alcohol was planned. Absolute alcohol was selected as the agent for the procedure because of its easy availability. Patient was positioned with the right side up and head end down. Two ml of absolute alcohol was injected slowly through the existing intrathecal catheter. The position was maintained for 15 minutes. She had dramatic pain relief after about 2 minutes of injection. The intrathecal catheter was kept in situ in case the need of a repeat block arose. This time the pain relief was permanent. The catheter was removed after 2 days. The patient remained pain free till she succumbed to her illness about one and half month later.

DISCUSSION: WHO prescribes a three step analgesic ladder for cancer pain management. ${ }^{1}$ The first step is non-opioid analgesics for mild pain; the second step being oral opioid analgesic for mild to moderate pain and the third step includes parenteral opoids with or without adjuvant drugs for severe pain. 


\section{CASE REPORT}

Non pharmacological technique include TENS, acupuncture and anaesthesiological interventions. Several studies are available using intermittent or continuous neuraxial blocks using local anaesthetics and opioids with or without adjuvant drugs and producing good to excellent pain relief for considerable period of time ranging from weeks to months. ${ }^{2,3,4}$ These procedures are now the gold standard of ultimate treatment of intractable pain of the extremities. tachyphylaxis was the main problem with this case. Ethanol, a hypobaric solution had been used extensively for neurolytic procedures in concentrations from $3-100 \%$ in the early 20 th century. ${ }^{5}$

It facts by destroying nerves and producing Wallerian degeneration without disruption of the schwann cell sheath. Thus axonal regeneration can and will occur sometimes resulting in neuroma formation. However, if cell body destruction occurs regeneration is not possible. Recent studies have shown that ethanol destroys nervous tissue by extration of cholesterol and other lipids and by protein precipitation. Topical application of alcohol to exposed nerves results in both axon and schwann cell destruction. It is rapidly removed from CSF in less than 10 minutes. ${ }^{6}$

When 3-6\% phenol is applied to peripheral nerves, both acute and chronic damage to axons and myelinoccur. In addition, protein coagulation and necrosis ultimately result in axonal and wallerian degeneration. Phenol is injected in a range of concentrations from $3 \%$ to $15 \%$ and has to be prepared fresh. ${ }^{7}$ The main drawbacks of neurolytic block are loss of bladder and bowel control. But these were of little significance as the patient was already bedridden and catheterized in our case.

CONCLUSION: Importance of pain management and palliative care is quite well known, and much advancement in forms of medication and other interventions have been made in the developed countries. Unfortunately this aspect of medical intervention still remains a neglected area in this part of the globe. However not all is lost as with proper planning and judicious use of available resources much can be done.

\section{REFERENCES:}

1. Who Expert Committee. Cancer pain relief and palliative care. World Health Organ Tech Rep Ser 1990; 804: 1-75.

2. Ballantyne JC, Carwood CM. Comparative efficacy of epidural, subarachnoid, and intracerebroventricular opioids in patients with pain due to cancer. Cochrane Database Syst Rev 2005; 1 : CD005178.

3. Bennet G. Burchiel K, Buchser E, et al. Clinical guideliness for intraspinal infusion: report of an expert panel. J Pain symptomManage 2000; 20: S37-43.

4. WA Chambers. Nerve Block in Palliative Care. BJA 2008; 101 (1): 95-100.

5. Constance Ottley. Intrathecal alcohol for relief of pain. BMJ 1938; 1(4026):510-512.

6. Rumbsy MG, Finean JB. The action of organic solvent on the mylin sheath of peripheral nerve tissue II: Short chain aliphatic alcohol. J Neurochem 1966; 13: 1509-1513.

7. Mark J. Lema. Invasive procedure for cancer pain. Pain Update VI-1 1998. 


\section{AUTHORS: \\ 1. K. Upendra Singh \\ 2. Kh. Lokeshwar Singh \\ 3. S. Thoibahenba Singh \\ 4. N. Charan \\ 5. Jonan Puni Kay}

\section{PARTICULARS OF CONTRIBUTORS:}

1. Assistant Professor, Department of Anaesthesia, Jawaharlal Nehru Institute of Medical Sciences, Imphal, Manipur.

2. Assistant Professor, Department of Medicine, Jawaharlal Nehru Institute of Medical Sciences, Imphal, Manipur.

3. Assistant Professor, Department of Anaesthesia, Jawaharlal Nehru Institute of Medical Sciences, Imphal, Manipur.

\section{FINANCIAL OR OTHER} COMPETING INTERESTS: None
4. Senior Resident, Department of Anaesthesia, Jawaharlal Nehru Institute of Medical Sciences, Imphal, Manipur.

5. Senior Resident, Department of Anaesthesia, Jawaharlal Nehru Institute of Medical Sciences, Imphal, Manipur.

\section{NAME ADDRESS EMAIL ID OF THE CORRESPONDING AUTHOR:}

Dr. K. Upendra Singh.

Department of Anaesthesiology,

JNIMS, Porompat, Imphal East,

Manipur-795004.

E-mail: drupendrakeisham@rediffmail.com

Date of Submission: 21/01/2015.

Date of Peer Review: 22/01/2015.

Date of Acceptance: 07/02/2015.

Date of Publishing: 16/02/2015. 